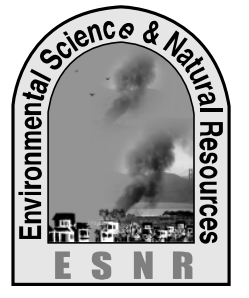

J. Environ. Sci. \& Natural Resources, 6(1): 53 - 57, 2013

ISSN 1999-7361

\title{
Flood Disaster Risk Reduction and Adaptation Around the Coastal Area of Bangladesh
}

\author{
M. S. Shaikh ${ }^{1}$, M. Shariot-Ullah ${ }^{2}$, M. A. Ali ${ }^{1}$ and A. K. M. Adham ${ }^{2}$ \\ ${ }^{1}$ Department of Environmental Science, ${ }^{2}$ Department of Irrigation and Water Management, \\ Bangladesh Agricultural University, Mymensingh-2202
}

\begin{abstract}
This study was undertaken to investigate the strategies for flood disaster risk reduction and adaptation around the coastal area of Bangladesh. Education level and environmental awareness, family size, farm size, adaptation tools, loss due to flood disaster, adaptation tools and area of the rivers and canals of the localities were taken as independent variables. On the other hand, pre and post flood activities were considered as dependent variable of the study. Pre flood activities such as miking around the flood disaster areas reduced flood risk $44.2 \%$, radio and TV bulletin $25.0 \%$, enclosure tube-well by polythene bag $16.7 \%$ and shifting the people to cyclone center reduced flood risk $14.2 \%$. However, post flood activities such as food and water supply contributed $48.3 \%$ and activities of medical rescue team (i.e. provide medicine, vaccination and saline) and agricultural inputs supply (i.e. seed, fertilizer, livestock's, fisheries) contributed the same percentage i.e. $25.8 \%$ to adapt flood disaster. These variables were tested to explore the relationship between the dependent and independent variables. Education level and environmental awareness, family size, farm size, adaptation tools, loss due to flood disaster were significantly correlated with the pre and post flood activities for flood disaster risk reduction and adaptation around the coastal areas. The findings indicated that the lower the education level and environmental awareness of the coastal area people the lower is the activities (pre and post) during flood disaster in flood disaster risk reduction and adaptation. The findings also indicated that the pre flood preparation is not enough for flood disaster risk reduction and adaptation around the coastal area of Bangladesh and adaptation tools were not sufficient for flood disaster risk reduction and adaptation around the coastal areas of Bangladesh.
\end{abstract}

Key words: Adaptation, Environmental awareness, Flood disaster, Risk reduction

\section{Introduction}

Bangladesh is the part of world's most dynamic hydrological and the biggest active delta system and flood is the regular monsoon event here. Extreme events of flood adversely affect the development, economy, poverty and almost every sector of Bangladesh. The coastal zone covers 19 districts, encompassing 153 upazilas. The zone constitutes 32\% area of Bangladesh and $28 \%$ of the population of Bangladesh (MoWR, 2005). In 12 of these districts, face a combination of flood, cyclone risk, salinity and tidal water movement above critical levels and are designated as "exposed coast". This exposed coast is vulnerable to flood (Islam et al., 2006). Bangladesh experiences floods almost every year with considerable damage. The floods of 1954, 1955, 1974, 1987, 1988, 1998, 2004, 2007 and 2010 caused enormous damages to properties and considerable loss of life (BWDB, 2010). Flood disaster has direct and indirect impacts on land resources and their uses comprising agriculture, shrimp and fish farming, forestry, urban development and other settlement needs. Lately the government has promulgated the Land Use Policy-2001, Coastal Zone Policy-2005, Tsunami Vulnerability Map-2005 and Coastal Development Strategy-2006. The government has also accepted an indicative flood plan. However, much remains to be done in implementing the recently adopted to flood disaster risk reduction plan and the establishment of Integrated Coastal Zone
Management, coordination, demarcation of land zoning, mangrove afforestation through community participation, better preparedness against flood (Islam, 2006). The up-gradation and modernization of Bangladesh's integrated risk management regime is vital for the country to continue the economic growth. The objectives of this study were i) to find out the flood disaster risk reduction strategies, ii) to identify the local adaptation strategies against the flood disaster and iii) to explore the relationship between activities (pre and post flood) and flood disaster risk reduction and adaptation around the coastal area of Bangladesh.

\section{Methodology}

The study was conducted in Pirojpur and Zianagar upazilla under Pirojpur district, Kachua and Morrelgong upazilla under Bagerhat district and Rupsha upazilla under Khulna district. From each upazilla two villages were selected for the specific study. This selection was made on the basis of flood occurrence in previous years $(1954,1955,1974$, 1987, 1988, 1998, 2004, 2007 and 2010). A total of 120 respondents of the selected villages constituted the population of the study. A pretested structured interview schedule containing both open and closed form questions was prepared. The interview schedule was pre-tested to identify faulty questions in the draft and necessary corrections and modification were made. The independent 
variables were measured as follows: Age of a respondent was measured by the period of time from his/her birth to the time of interview. Education level and environmental awareness of the respondents was measured on the basis of completed years of schooling by the respondent in the educational institutions. A score of one was given for each completed year of schooling and additional one is given for environmental awareness. Family size of a respondent was compute by counting the total members jointly lived together in the same family including respondents. Farm size (FS) of a respondent was determined by counting total area under farming operations and being estimated in terms of full benefit using following formula:

$\mathrm{FS}=\mathrm{A}_{1}+\mathrm{A}_{2}+\mathrm{A}_{3}$

Here, $\mathrm{A}_{1}=$ Homestead area, $\mathrm{A}_{2}=$ Area under cultivation, $\mathrm{A}_{3}=$ Area under share cropping.

Losses of livestock, rice, fish population, human health due to flood disaster was estimated in taka. Data about adaptation tools were collected by taking shelter belt, shallow tube-wall, cyclone center, embankment and boat in consideration. Data related to area of river and canals were collected from BBS report of different years. The dependent variables were measured as follows: Pre and post flood activities were measured on the basis of activities were taken by the local people to flood disaster risk reduction and adaptation. The pre-flood activities were miking around the coastal area, warning through radio and TV bulletin, enclosure of tube-well by polythene bag, shifting the people to cyclone center. The post-flood activities were food and water supply, activities of medical rescue team and agricultural inputs supply to the flood affected people. Data were collected to identify flood preparedness of the coastal area people. Local adaptation data were also collected to identify adaptation strategies of the coastal area people. For scoring one (1) mark was given if respondent adopt any of these post- flood activities. After completion of data collection, the collected raw data were coded, compiled, tabulated and analyzed by using SPSS computer package.

\section{Results and discussion}

\section{Age of the respondents}

The highest proportion (39.2\%) of the respondent fall in the middle aged category, while 38.3 and $22.5 \%$ belonged to young aged and old aged categories, respectively (Table 1). It is evident that young and middle aged groups of people have more physical and mental abilities and also are more innovative than old aged people. Thus people belonging to middle aged category might take more initiatives to flood disaster risk reduction and adaption. Bhattacharyya (2008) was also reported the same phenomena.

Table 1. Age of the respondents

\begin{tabular}{lccc}
\hline Group & Frequency & Percent & Mean (years) \\
\hline Young (>30 years ) & 46 & 38.3 & \\
Middle(30-40 years) & 47 & 39.2 & 35.08 \\
Old (<40 years) & 27 & 22.5 & \\
\hline Total & 120 & 100.0 & \\
\hline
\end{tabular}

\section{Education level and environmental awareness}

Based on educational qualification scores, the respondent were classified into five different categories as shown in Fig. 1. The figure indicates that $4 \%$ of the respondent were illiterate, $26 \%$ respondents could sign only, while $58 \%$ percent had primary level, $9 \%$ had primary pass and 3\% had higher level education. Education broad the power of understanding and develop the abilities of analyzing facts and situation in order to take correct decision. The low level of education among the coastal people in this study indicates traditional backwardness.

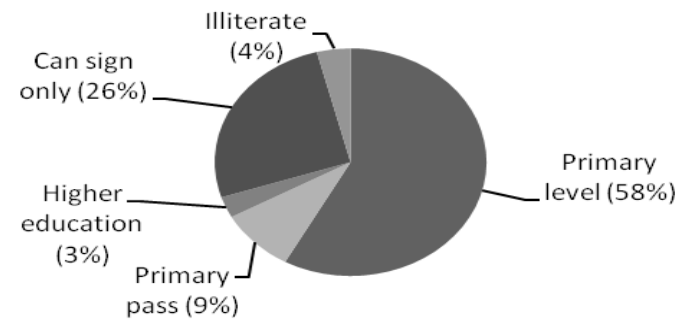

Fig. 1. Percentage of education level of the respondents 


\section{Family size of the respondents}

The average family size of the respondents was equal to the national average i.e. $4.80 \%$ (BBS, 2002). However, the large families were mostly characterized as joint family always busy for earning life expense, keeping away from awareness program (Table 2).

Table 2. Family size of the respondents

\begin{tabular}{lcccc}
\hline Family size & Frequency & Percent & Mean & SD \\
\hline Large & 37 & 30.8 & & \\
Medium & 77 & 64.2 & 4.82 & 1.23 \\
Small & 6 & 5.0 & & \\
\hline Total & 120 & 100.0 & & \\
\hline
\end{tabular}

Farm size of the respondents

Farm size scores of the coastal people varied from 0.02 to 3.01 acre. The study explored that $30.0 \%$ of the respondents belonged to the large farm

Table 3. Farm size of the respondents category, $11.7 \%$ belonged to small farm category and the rest $58.3 \%$ to medium farm category (Table 3).

\begin{tabular}{lcccc}
\hline Farm size (acre) & Frequency & Percent & Mean (acre) & SD \\
\hline Small $(0.02-0.2)$ & 14 & 11.7 & \multirow{2}{*}{0.85} & 0.80 \\
Medium (0.2-1.0) & 70 & 58.3 & & \\
Large (1.0-3.0) & 36 & 30.0 & & \\
\hline Total & 120 & 100.0 & & \\
\hline
\end{tabular}

\section{Losses due to flood disaster}

Highest percentage of the property loss $(85.0 \%)$ occurred due to flood was below Tk. 50000 and lowest $(3.3 \%)$ was occurred in respect to above

Table 4. Table total loss due to flood
Tk. 1, 00,000. It indicates that coastal people being medium income and took no initiatives to reduce flood loss.

\begin{tabular}{lcccc}
\hline \multicolumn{1}{c}{ Total loss } & Frequency & Percent & Mean (Tk.) & SD \\
\hline Bellow Tk. 50000 Tk & 102 & 85.0 & & 4503.15 \\
Tk. 50000-100000 Tk & 14 & 11.7 & 6707.500 & \\
Above Tk. 100000 Tk & 4 & 3.3 & & \\
\hline Total & 120 & 100.0 & & \\
\hline
\end{tabular}

\section{Adaptation tools}

The study explored, highest percentages occupied by shallow tube-well $(50.0 \%), 25.8 \%$ by shelter belt, $16.7 \%$ by cyclone center, $7.5 \%$ by embankment (Table 5). The availability of shelter belt and embankment were not sufficient. This adaptation tools should be increased.

Table 5. Adaptation tools used in the study areas

\begin{tabular}{lcccc}
\hline Adaptation tools & Frequency & Percent & Mean & SD \\
\hline Shallow tube-well & 60 & 50.0 & & \\
Shelter Belt & 31 & 25.8 & 1.82 & 0.97 \\
Cyclone Shelter & 20 & 16.7 & & \\
Embankment & 9 & 7.5 & & \\
\hline Total & 120 & 100.0 & \\
\hline
\end{tabular}

\section{Pre flood activities}

Pre flood activities contributed significantly to reduce flood disaster such as miking around the flood disaster areas contributed $44.2 \%$, radio \& TV bulletin
$25.0 \%$, enclosure of tube- well by polythene bag $16.7 \%$, shift the people to cyclone center $14.2 \%$ (Table 6). These were not sufficient to reduce loss due to flood. Activities should be strengthened. 
Table 6. Pre-flood activities in the study areas

\begin{tabular}{|c|c|c|c|c|}
\hline Pre-flood activities & Frequency & Percent & Mean & SD \\
\hline Miking around disaster areas & 53 & 44.2 & \multirow{4}{*}{2.01} & \multirow{4}{*}{1.09} \\
\hline Warning through Radio \& TV bulletin & 30 & 25.0 & & \\
\hline Keep tube-well by polythene bag & 20 & 16.7 & & \\
\hline Shift the people to cyclone shelter & 17 & 14.2 & & \\
\hline Total & 120 & 100 & & \\
\hline
\end{tabular}

Area of rivers and canals of the localities

Fig. 2 shows that the area under river reduced drastically. In 1995 area of the river is approximately
$30 \%$ reduced to 2009 . The area of the river reduced 4305 acre from 1995 to 2009 in Morrelgong. For this reason this place was more vulnerable to flood.

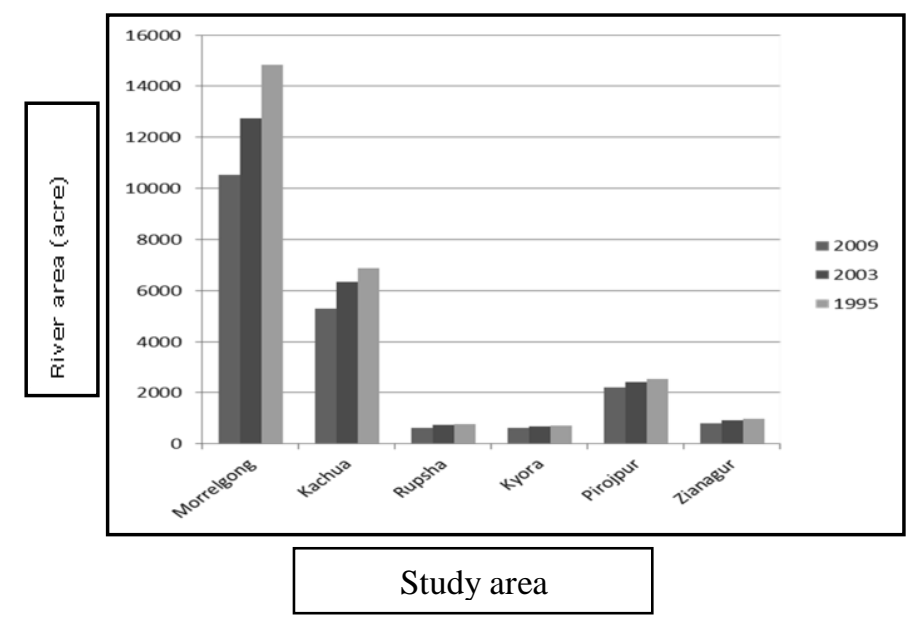

Fig. 2. Yearly variation of river area in the study area

\section{Post flood activities}

Post flood activities like food and water supply contributed to adapt flood $48.3 \%$, activities of medical rescue team $25.8 \%$, seed and fertilizer supply $25.8 \%$ shown in Fig. 3. Highest percentage was occupied by food and water supply to affected areas it was pivotal for risk reduction of flood in coastal area. Same percentage occupied by possible medical rescue team seed and fertilizer.

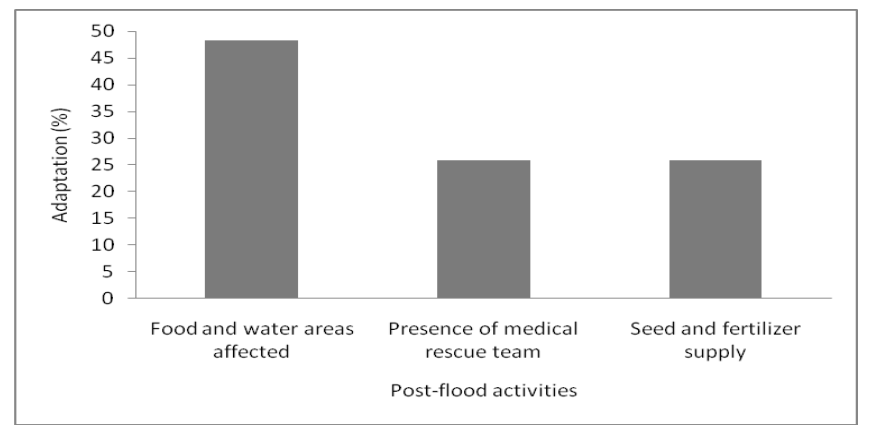

Fig. 3. Percentages adaptation of post flood activities

Relationship between the selected characteristics of the respondents and pre and post flood activities Education level and family size of the coastal area people had a significant relationship with activities during flood disaster in risk reduction and adaptation around the coastal area of Bangladesh. The findings indicated that the lower is the education level and environmental awareness of the coastal area people, the lower the activities in flood disaster risk reduction and 
adaptation. The total loss and adaptation tools of the coastal area people had also significant relationship with activities during flood disaster in risk reduction and adaptation around the coastal area. The findings indicated that the pre flood preparation is not enough and the adaptation tools (STW, Boat, Shelter belt, Cyclone center,
Embankment) were not sufficient for flood disaster risk reduction and adaptation around the coastal area (Table 7). Age and farm size of the coastal area people had no significant relationship with activities during flood disaster in flood disaster risk reduction and adaptation around the coastal area (Table 7).

Table 7. Correlations with variables

\begin{tabular}{|c|c|c|c|c|c|c|c|c|c|}
\hline & Age & $\begin{array}{c}\text { Educatio } \\
\mathrm{n}\end{array}$ & Family size & $\begin{array}{l}\text { Farm } \\
\text { size }\end{array}$ & $\begin{array}{c}\text { Total loss, } \\
\text { Tk }\end{array}$ & Rescue & Tools & $\begin{array}{l}\text { Pre-flood } \\
\text { activity }\end{array}$ & $\begin{array}{c}\text { Post-flood } \\
\text { activity }\end{array}$ \\
\hline Age & 1 & 0.13 & 0.06 & 0.09 & 0.10 & $-0.21(*)$ & 0.08 & -0.01 & 0.05 \\
\hline Education & 0.13 & 1 & $0.26(* *)$ & -0.12 & $-0.24(* *)$ & $0.33(* *)$ & $0.50(* *)$ & $0.39(* *)$ & $0.66(* *)$ \\
\hline Family size & 0.06 & $0.26(* *)$ & 1 & -0.03 & $-0.26(* *)$ & 0.17 & $0.40(* *)$ & $0.31(* *)$ & $0.40(* *)$ \\
\hline Farm size & 0.09 & -0.12 & -0.03 & 1 & 0.01 & 0.06 & 0.09 & 0.12 & 0.02 \\
\hline Total loss, Tk & 0.10 & $-0.24(* *)$ & $-0.26(* *)$ & .011 & 1 & -0.12 & $-0.38(* *)$ & $-0.31(* *)$ & $-0.37(* *)$ \\
\hline Rescue & $-0.21(*)$ & $0.33(* *)$ & 0.17 & 0.06 & -0.12 & 1 & $0.30(* *)$ & $0.39(* *)$ & $0.47(* *)$ \\
\hline Tools & 0.08 & $0.50(* *)$ & $0.40(* *)$ & 0.09 & $-0.38(* *)$ & $0.30(* *)$ & 1 & $0.83(* *)$ & $0.82(* *)$ \\
\hline Pre-flood activity & -0.011 & $0.39(* *)$ & $0.31(* *)$ & 0.12 & $-0.31(* *)$ & $0.39(* *)$ & $0.83(* *)$ & 1 & $0.69(* *)$ \\
\hline $\begin{array}{l}\text { Post-flood } \\
\text { activity }\end{array}$ & 0.05 & $0.66(* *)$ & $0.40(* *)$ & 0.02 & $-0.37(* *)$ & $0.47(* *)$ & $0.82(* *)$ & $0.67(* *)$ & 1 \\
\hline
\end{tabular}

* Correlation is significant at the 0.05 level (2-tailed).

** Correlation is significant at the 0.01 level (2-tailed). List wise $\mathrm{N}=120$

\section{Conclusions}

Based on the findings of the study and their interpretations, the following conclusions were furnished. For reducing flood risk four pre-flood activities were taken such as: Miking around the coastal area contributed $44.2 \%$, radio and TV bulletin contributed $25.0 \%$, enclosure of the tubewell by polythene contributed to reduce flood 16.7 $\%$ and shifting the flood affected people to cyclone center cotributed $14.2 \%$ to reduce flood risk. Beside this, for adapting flood risk three post-flood activities were taken. Such as: Food and water supply contributed $48.3 \%$, agricultural inputs (i.e. seed, fertilizer, livestock's, fisheries) contributed $25.8 \%$, availability and services provided by medical rescue team (i.e. medicine, vaccination, saline) contributed $25.8 \%$ to reduce flood disaster vulnerability. Education level and environmental awareness, family size, farm size, adaptation tools, loss due to flood disaster of the respondent were significantly correlated with the pre and post flood activities for flood disaster risk reduction and adaptation around the coastal area. The findings indicated that the lower the education level and environmental awareness, the lower is the activities in flood disaster risk reduction and adaptation. The findings also indicated that the pre-flood preparation was not enough and adaptation tools were not sufficient around the coastal area. Though there was opportunity to reduce the risk of flood by strengthening the activities of other adaptation tools by de-sedimentation and protected river from illegal occupy.

\section{References}

BBS. 2002. Statistical year book of Bangladesh, Bangladesh Bureau of Statistics, Dhaka.

BWDB. 2010. Annual flood report. Bangladesh Water Development Board, Flood forecasting and warning centre.

Bhattacharya, P. 2008. Integrating local knowledge with early warning system for disaster risk reduction centre for disaster management, Tata Institute of Social Sciences, Mumbai, India.

Islam, M. R., Ahmad, M. and Osman, M. S. 2006. State of the coast 2006. Program development office for integrated coastal zone management plan project, Water resources planning organization, Dhaka.

Islam, R. 2006. Pre and post tsunami coastal planning and land use policies and issues in Bangladesh. In Proceedings of the workshop on coastal area planning and management in Asian tsunami-affected countries, Bangkok, Thailand.

MoWR, 2006. Coastal development strategy. Ministry of water resources, Government of the People's Republic of Bangladesh. 